Supplement of Atmos. Chem. Phys. Discuss., 15, 35313-35381, 2015

http://www.atmos-chem-phys-discuss.net/15/35313/2015/

doi:10.5194/acpd-15-35313-2015-supplement

(C) Author(s) 2015. CC Attribution 3.0 License.

(c) (i)

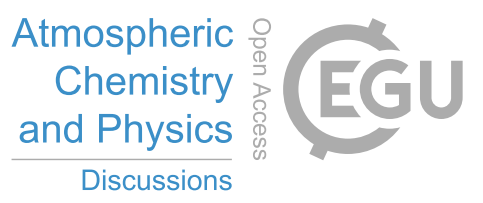

Supplement of

\title{
Modeling the reactive halogen plume from Ambrym volcano and its impact on the troposphere with the CCATT-BRAMS mesoscale model
}

L. Jourdain et al.

Correspondence to: L. Jourdain (line.jourdain@cnrs-orleans.fr)

The copyright of individual parts of the supplement might differ from the CC-BY 3.0 licence. 


\section{Supplementary material:}

2

3

4

5 5

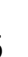

\section{Sensitivity study to the height of the plume}

Knowledge of the injection altitude of volcanic emissions is critical to study the transport, the chemical evolution and the deposition of theses emissions. We performed an additional simulation (S1_HighT_alt) in which emissions are injected at $2000 \mathrm{~m}$ into a grid-box of about 200-300 m depth. This higher plume altitude estimate was suggested by Bani et al. (2012) but is based only on visual estimations which are known to be rather uncertain.

Figure $1 \mathrm{~S}$ shows that the $\mathrm{SO}_{2}$ columns are less well simulated by the model in the S1_HighT_alt than in the S1_HighT simulation. The plume seems to be transported too much towards the east relative to the observations. As a result, the simulation S1_HighT_alt underestimates the observation by $44 \%$ for $\mathrm{SO}_{2}$ (compared to $2 \%$ for S1_HighT). The correlation between simulated and observed $\mathrm{SO}_{2}$ is also reduced, 0.37 (compared to 0.61 for S1_HighT). This difference with S1_HighT is likely due to stronger and more north-westerly winds at $2000 \mathrm{~m}$ acting to decrease $\mathrm{SO}_{2}$ columns. $\mathrm{BrO}$ columns are similarly underestimated by $83 \%$ in S1_HighT_alt (compared to $40 \%$ for the standard simulation S1_HighT), mostly due to the fact that total bromine is reduced for the same reason as for $\mathrm{SO}_{2}$ by the shift in direction of plume transport (Figure 2S). 

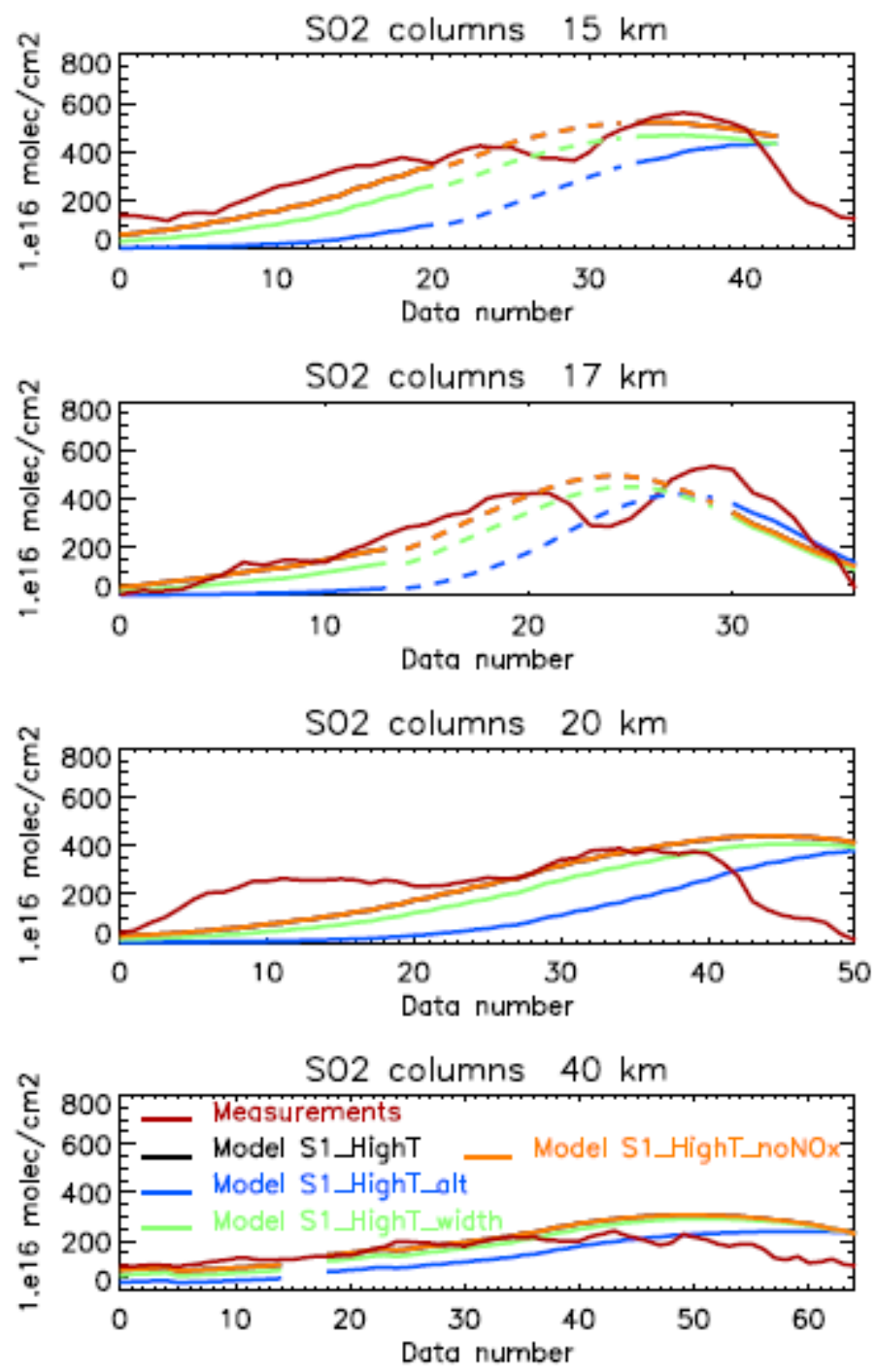

Figure 1S: Comparison between $\mathrm{SO}_{2}$ columns observed by Bani et al. (2009) (red line) and simulated by the model for S1_HighT (black line) and for the sensitivity simulations: S1_HighT_alt (blue line), S1_HighT_width (green line), S1_HighT_noNOx (orange line).

32 Note that black and orange lines are on top of each other (superimposed). The method of comparison is the same than Figure 3. 

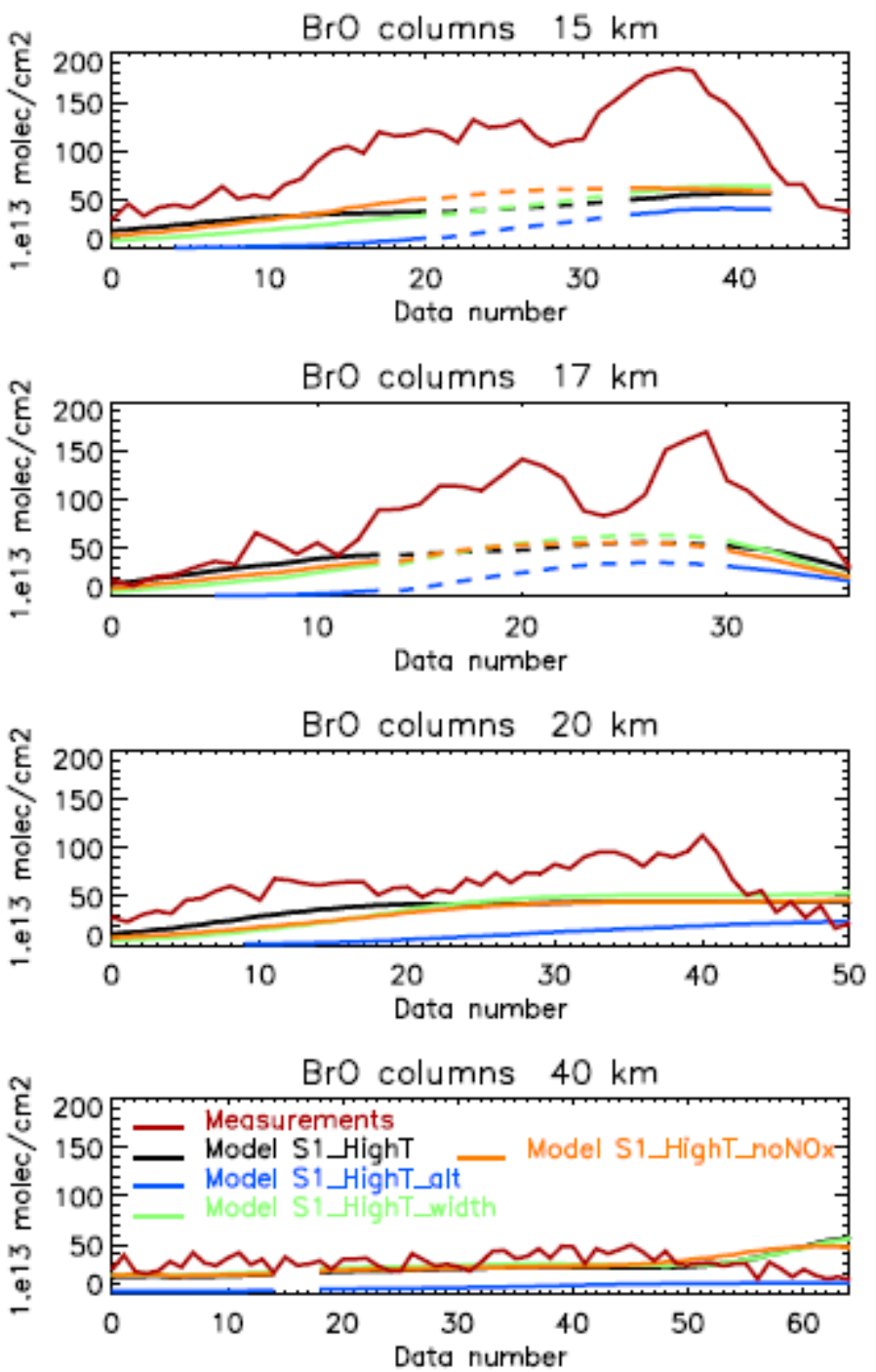

Figure 2S: Comparison between BrO columns observed by Bani et al. (2009) (red line) and

37 simulated by the model for S1_HighT (black line) and for the sensitivity simulations:

38 S1_HighT_alt (blue line), S1_HighT_width (green line), S1_HighT_noNOx (orange line).

39 The method of comparison is the same than Figure 3. 

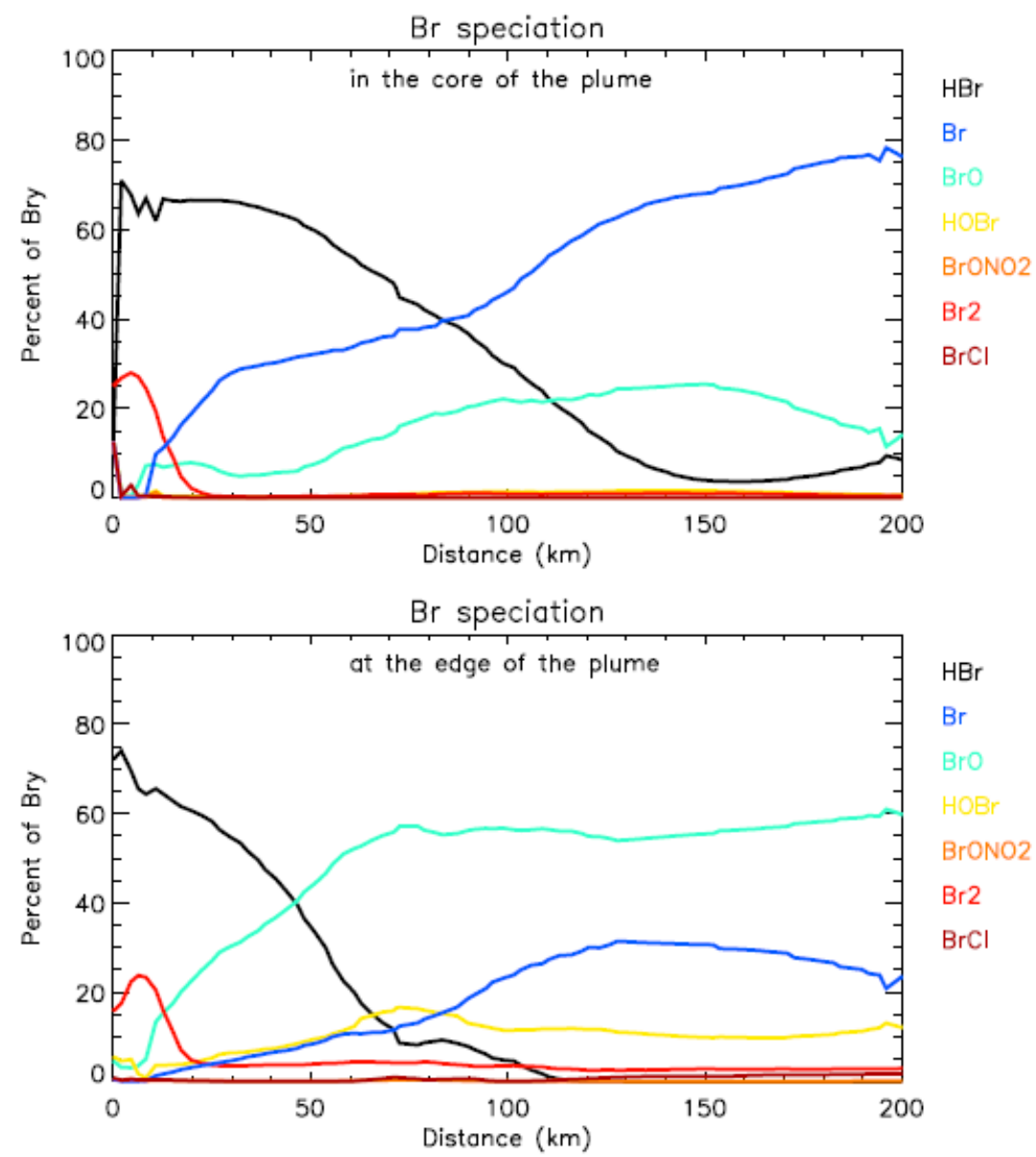

44 Figure 3S: $\mathrm{Br}$ speciation along the plume (in the core and at the edge) in the simulation 45 S1_Hight_noNO ${ }_{x}$ and the grid $2 \mathrm{~km} \mathrm{x} 2 \mathrm{~km}$ the 12th of January 2005 at 06 UT. The Br speciation has been calculated as the percent of Bry $\left(\mathrm{Bry}=\mathrm{HBr}+2 \mathrm{Br}_{2}+\mathrm{BrCl}+\mathrm{Br}+\mathrm{BrO}+\right.$ $\mathrm{HOBr}+\mathrm{BrONO}_{2}$ ). Distance is calculated from the middle of the gridbox containing Marum and Benbow 


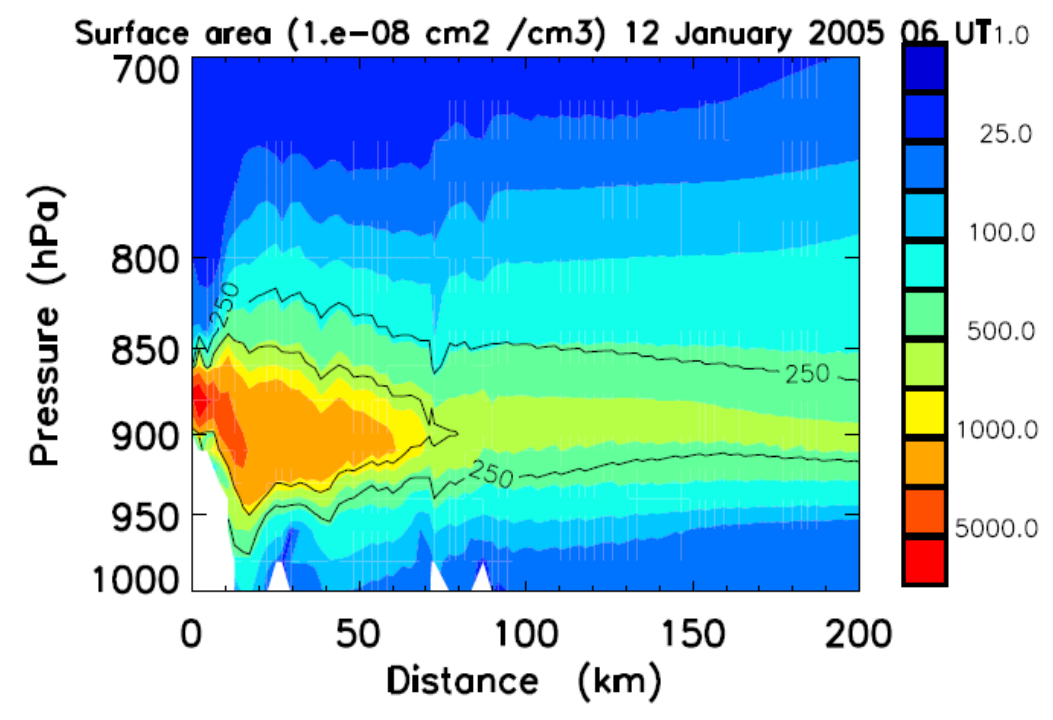

51

52 Figure 4S: Distance-Pressure cross section of the aerosol surface area density $\left(\mu \mathrm{m}^{-2} / \mathrm{cm}^{3}\right)$ in 53 the plume of Ambrym on the $12^{\text {th }}$ January 2005 in the simulation S1_HighT. 